\section{The good, the bad and the ugly}

\section{Hermann Bondi}

Truth and Beauty: Aesthetics and Motivations in Science. By S. Chandrasekhar. University of Chicago Press: 1987. Pp. 170. \$23.95, £19.25.

WhAT a splendid book! Reading it is a joy, and for me, at least, continuing reading it became compulsive.

The fact that this is a collection of lectures (one from 1946, the others bearing dates in the period 1975-1986) means that each of the sections is self-contained, yet there is almost no overlap or repetition. Chandrasekhar is a distinguished astrophysicist and every one of the lectures bears the hallmark of all his work: precision, thoroughness, lucidity. What perhaps I had not foreseen is the depth of the author's historical scholarship. I hasten to add that it was clear to me that if Chandrasekhar was willing to talk about historical or artistic matters, his study would be thorough to perfection; what was not obvious was that so many aspects of these subjects would figure in his lectures.

The last three lectures deal respectively with Milne, Eddington and Karl Schwarzschild, while an earlier group of them concentrates on Shakespeare, Newton and Beethoven. Others are more general. Yet in each case the book is enlivened by reference to events of which the author has personal knowledge, and, for those of us in the know, the discreet references to his own massive contributions are clear and most helpful. For me, born too late to have more than slight personal knowledge of Eddington and of Milne, Chandrasekhar's acute, friendly, yet not uncritical analysis is touchingly effective in helping me see them in the round.

I trust no reader of this review can have missed my enthusiasm for the book, yet I must also add some critical remarks because some aspects of the contents do not fit well into my picture of science. First, to a staunch disciple of Popper like myself, what philosophy of science there is in the book is incomplete, because it does not have any kind of Popperian perspective. Secondly, the very title of the book grates on me (though, fortunately for my enjoyment of it, this turns out to be irrelevant). I am perhaps even more cautious than Popper in assigning truth to science, and also have little faith in the usefulness of beauty as a guiding light. Not only am I bothered by the subjectivity of a judgement of beauty, but it seems to me either to have misled people or to have arisen only well after the original contribution. Thus Chandrasekhar writes so well and so rightly about the irrelevance to later science of much of the later work of Eddington, of Einstein and of Milne. This work was guided far too much by considerations of beauty, especially mathematical beauty, and far too little by hard, dirty physics.

Again, when Dirac, in his first outstanding contribution, produced the relativistic equation for the electron, its clumsiness and hence ugliness was pronounced. Later work, by Dirac and others, led to new mathematical formulations outstanding in their beauty. Equally, when black holes first arose in the theory, there was nothing particularly elegant about the equations. Much later, Chandrasekhar himself, in his

\section{Buzz-words}

\section{Wayne M. Getz}

The Biology of the Honey Bee. By Mark Winston. Harvard University Press:1987. Pp.281. \$29.95, £23.95.

Books about honey bees are like editions of encyclopaedias. Of both we ask what is new, is the material more readable than in other editions, is the emphasis on a particular branch of knowledge, and at what level is the material presented? In reviewing The Biology of the Honey Bee, I will deal with these questions one by one.

The title of the book is apt. Winston presents the full spectrum of basic honey bee biology, in contrast to Seeley in Honeybee Ecology (Princeton University Press, 1985) or von Frisch in his exhaustive treatise The Dance Language and Orientation of Bees (Harvard University Press, 1967), both of whom concentrated on particular aspects of the subject. The book is intended for biologists who would like to learn more about the honey bee. To quote Bernd Heinrich from the dust jacket, it also provides ". . . a wonderful reference and entrée to the literature on anything you ever wanted to know about honeybees". For the scientifically wellread non-biologist, a number of the chapters make interesting reading, especially those on worker activities (including nest building, foraging and communication), and reproductive and swarming behaviour. The physiologically orientated chapters, however, which include discussions on the role of juvenile hormone in caste development and the comparative function of the two queen hormones, 9-keto- $(E)-2$ deconoic and 9-hydroxy-(E)-2-deconoic acids, are unlikely to appeal to a general audience.

Honey bees have been particularly well studied because they are the species of insect that is most economically beneficial to human beings and because their social behaviour (together with that of their ant splendid book The Mathematical Theory of Black Holes, put together his own work and that of many others to reveal a pattern of outstanding beauty.

I do not wish to deny that giving earlier discoveries such concise, elegant descriptions is enormously useful for subsequent workers, but evidently it did not contribute to the original discovery. Beauty may be an excellent guide in mathematics, but I doubt its value in physics.

This slightly petulant display of my, perhaps heterodox, views should not stop any potential reader from enjoying this excellent book, as I did so fully.

Sir Hermann Bondi is Master of Churchill College, Cambridge CB3 ODS, UK.

relatives) represents a pinnacle of invertebrate evolution. Thus the honey bee is an ideal 'case-study' insect, and Winston's book will serve excellently for students, either as an advanced undergraduate reader or as a basis for a graduate seminar course that leads into the literature (with over 800 references, both the historical and current literature are covered comprehensively). The book should also satisfy professional biologists who would like to see how physiology, behaviour and ecology come together in mediating the organization of a complex insect society, and it can profitably be read by apiculturists wishing to learn more basic bee biology.

The style of writing is clear and relatively informal, making for easy reading in all but the most technical sections. Winston's love for his subject occasionally penetrates through his matter-of-fact style with such phrases as "drones are magnificently constructed for this one task [mating]". There was only one discussion in the book that I had a problem following for lack of clarity. This was the explanation of why workers will not maximize their foraging efficiency by only returning when their crops are full (second paragraph page 180).

If I were asked to fault this book, it would be for the omission of a chapter on apiculture. Winston might argue that his aim was to deal with the basic biology of the bee, and that apicultural aspects can only be treated in detail, as several other authors have already done. However, a 15-20-page chapter on the topic would have rounded off an otherwise complete picture of the honey bee. After all, almost every topic that Winston deals with can itself be greatly expanded, so insufficient depth is no argument for ignoring the symbiotic relationship between honey bees and human beings. Perhaps like a Persian rug, a near-perfect intermediatelevel book on honey bees requires a flaw to appease the gods.

Wayne M. Getz is a Professor in the Department of Entomology, University of California at Berkeley, California 94720, USA 